\title{
Characteristics of Fascia in Reference to Treatment Possibilities of Chosen Hand Diseases
}

\author{
Alicja Jurecka ${ }^{1 *}$, Maciej Papież ${ }^{2}$ and Artur Gądek ${ }^{1}$ \\ ${ }^{1}$ Jagiellonian University Medical College, Faculty of Health Sciences, Department of Orthopedics and Physiotherapy, Poland \\ ${ }^{2}$ Emirates Specialty Hospital, Dubai Healthcare City, Dubai
}

*Corresponding author: Alicja Jurecka, Jagiellonian University Medical College, Faculty of Health Sciences, Department of Orthopedics and Physiotherapy, Poland

\section{ARTICLE INFO}

Received: 慧 August 13, 2020

Published: 幽 August 31, 2020

Citation: Alicja Jurecka, Maciej Papież, Artur Gadek. Characteristics of Fascia in Reference to Treatment Possibilities of Chosen Hand Diseases. Biomed J Sci \& Tech Res 29(5)-2020. BJSTR. MS.ID.004874.

\section{ABSTRACT}

The patomechanism of changes encountered in many movement system dysfunctions gives a basis for applying manual techniques, which have an impact on fascia's structure, on treatment of chosen orthopedics afflictions.

Keywords: Fascia; Orthopedics; Hand diseases; Myofascial therapy; Physiotherapy

\section{Introduction}

An architecture of fascia and its precise connections with many od movement system components creates a basis for putting forward presumptions of prospects of applying a fascial modelling as an important element in many orthopedic afflictions treatment. Three-dimensional fascial web covers and penetrates such structures as: muscles, intermuscular septum's, tendons, ligaments, retinaculum's, periosteum, perineurium or dura mater. Fascia of those structures is not a separate connective tissue formation, but it bonds adjacent tissues into functional unity [1,2]. Pathological process within one of those structures will therefore effect with dysfunctions on many regions of fascial system.

\section{Mini Review}

The fascia is an anatomical structure that corresponds with dense connective tissue. Its characteristic feature is the presence of collagen fibers with minor amount of basic substance. Those properties give the tissue a net structure. It means that the fascia fibers run in several directions and at several interchanging angles, they can create a regular or irregular texture [3]. The main building material is type I collagen and highly hydrated proteoglycans $[3,4]$. By virtue of those components, fascia fibers are stretchable and plastic, and also resistant to mechanic stimulus. The current definition of the fascia emphasizes its meaning in tensional force transmission [5]. Collagen layers of the fascia are separated from each other by fatty tissue [2]. The outermost layer of the fascia is known as pinnacular or superficial. Next, in the trunk area, there is the investing fascia, also known as the deep fascia [6]. The investing fascia can be divided more specific into the epimysium, covering muscles, the peritenon, covering tendons and ligaments, and the periosteum, covering bones. Under the axial layer, there are fascia surrounding nerve structures, known as the epineurium and visceral fascia, covering internal organs. Stecco [7] disagreed, using superficial, deep, visceral, parietal followed by the name of the structures they cover.

Branches of this connective tissue create a basis for all body organs, fill free spaces between them and connect them with each other. More regular fibers are the basic components of tendons and intermuscular septum, separating muscle groups from each other and intergemellar septum of muscles. They secure the fibrous and histological continuity of the anatomical structures of the body [2]. Fascial fibers, along with the corresponding muscles or muscle groups, create a structural chain, becoming a connection between 
at least two adjacent units in vertical alignment. Myofascial chains are therefore paths, embracing distant muscle groups, including the surrounding fascia. These connections originate from the initial attachment of one muscle and go through the attachments of another muscle and are linear to the muscle fibers from head to toe $[7,8]$. There are four main anatomy trains in the upper limb. Each of them presents superficial and deep patterns, both on the anterior and posterior side. The anterior anatomy trains seem to be most significant from the clinical point of view. Superficial lines are characterized by a subcutaneous straight route.

The superficial front line (SFL) of the upper limb is a fascial line, running along the anterior part of the limb, which, while starting from the greater pectoral muscle, it runs through the medial intermuscular septum, the flexor muscles of the forearm, up to the palmar aspect muscles. A detailed description of the SFL of the upper limb specifies the latissimus dorsi, together with the teres major and the greater pectoral muscle, the bands of fascial fibers of which join into the medial intermuscular septum of the arm, separating in this way the muscle groups of the flexors and extensors. Then, at the attachment site of the anterior muscle group of the forearm, another muscular-fascial train begins, formed by the radial flexor muscle of the wrist, the long palmar muscle, the ulnar flexor muscle and the superficial flexor muscle of the fingers. The superficial front line of the upper limb controls the driving force of the upper limbs in forward and lateral motions [8]. The route of the deep anatomy trains of the upper limb is more complex. The deep front line (DFL) of the upper extremity runs on the anterior side of limb, starting from the minor pectoral muscle and running through the biceps brachii, the coracobrachialis, the brachialis and the radial bone, up to the thenar muscles. The deep muscle-fascia line also includes the deep flexor muscle of the fingers, the long flexor muscle of the thumb and the pronator teres, i.e. the muscles that form the deep layer of the front muscle group of the forearm.

The DFL of the upper extremity plays a stabilizing role, participating, among other actions, in coordinated motions, as well as in the grasping motions of the thumb $[2,7,8]$. From the tissue physiology point of view, the fascia has been characterized as strong [9], but flexible [10], demonstrating piezoelectric properties, revealing varying rigidity with changing hydration [11], rich in nerve endings $[12,13]$, containing a fairly high number of mechanoreceptors and able to undergo small contractions $[14,15]$. Its structure becomes denser [16] and thicker along the vector of the active force, which, in turn, increases it rigidity in that direction [17]. The fascia surrounds each muscle and organ in the body [10]. Its functions include motion stabilisation [18] and load transfer, not only between adjacent muscle fibres but also between muscle bundles $[19,20]$. It protects blood and lymphatic vessels [21], secures muscles against damage from excessive stretching [20] and protects adjacent structures from rubbing against each other [22]. The fascia also influences the venous return, ensuring appropriate drainage $[23,24]$, improves the coordination process and enhances the muscle functionality, ensures proper tension within the musculoskeletal system [25] and suppresses the spread of infections [26]. It has been demonstrated that a more rigid fascia supports the force responsible for load transfers among muscles [27].

Due to the presence of Golgi tendon organs (GTO), Ruffini corpuscles (Bulbous corpuscles) and Pacinian corpuscles, this tissue takes part in the generation of the reflex to stretching [10], as well as in proprioception [12] and nociception [28] processes. Changes are observed in fascia structures in the process of ageing. Its viscoplastic properties deteriorate with age, with a higher tendency towards the occurrence of adhesions and densifications [16]. Collagen, when submitted to loads, rebuilds its structure $[28,29]$, while oestrogens play a significant role in the process stimulation [30]. The properties of the fascia may also be changing as a result of muscle lesions or surgical intervention [31]. A pathological process within the fascia triggers inflammation, which may be a potential cause of pain [32]. Wrong motion patterns or imposed immobilisation may cause the formation of bridges between adjacent fascia layers, leading to adhesions [33]. Therefore, interventions into fascia structures would seem fairly appropriate, supporting the healing process of many orthopaedic or neurological conditions. Some scientific reports suggest that the proper manual stimulation may provide positive modelling of fascia structures in pathological conditions [34-41].

A case report, describing a patient after reconstruction of the anterior cruciate ligament (ACL), shows the positive effects of manual-fascial therapy with a rapid improvement of muscle activity [42]. In addition, the preliminary results of studies carried out among patients after a total knee replacement, proved efficacy of the manual-fascial therapy in motion recovery and in improved activity of the muscles responsible for the proper functionality of the knee joint [43]. In the mentioned study, the therapy was provided to the patients only once, which provides no grounds to draw more general conclusions regarding its applicability. At the same time, it encourages the undertaking of studies, leading to an assessment of the efficacy of the fascial therapy to be included in the global, long-term process of improving patient functionality after knee alloplastic procedures.

Among orthopedic conditions, localized within the upper extremity, the highest incidence rates are demonstrated by carpal tunnel syndrome and the Dupuytren's contracture. The initial symptom of Dupuytren's contracture is the occurrence of a hole on the palmar side of the hand, especially at the region of the distal palmar groove. The holes are formed as a results of the changing route of the fibers of the palmar aponeurosis, connected with the subcutaneous fascia. Stimulation of the vertical bridges leads to the progression of changes [44]. 
The palmar aponeurosis runs subcutaneously shallow and, due to its thin fibrous plate, it tightly adheres to the skin. The palmar aponeurosis is formed of two layers: shallower, with longitudinally running fibers, and deeper with transversely running fibres, spanning above the metacarpal bone heads. Both layers adhere closely to each other. The long palmar muscle tendon fibres integrate into the superficial layer of the palmar aponeurosis, stretched by the long palmar muscle. Cases occur, in which there is no long palmar muscle, that affects the structure and route of the fibres in the superficial layer of the palmar aponeurosis [24,45]. It proves the effects of the traction force from the long palmar muscle on the palmar aponeurosis structure. The antebrachial fascia, on the other hand, is integrated into the deep layer of the palmar aponeurosis. In turn, tunnels for the flexor muscle tendons of the fingers are formed from the fibrous plate that covers the palmar aponeurosis. The presented anatomical connections of the palmar aponeurosis with other structures provide grounds to apply the fascial therapy as a form of treatment of the Dupuytren's contracture, within a broader programme of prophylactic or postoperative physiotherapy.

It has been demonstrated in preliminary studies, carried out in patients after surgical treatment of Dupuytren's contracture, that a manual therapy, applied in the regions of the joined structures in the fascial line, quickly improves the functionality of the hand, regardless of the number of fingers affected by the disease [46]. At the same time, the above-mentioned results of the studies raise hopes for the application of the therapy, intervening in the fascia structure in various groups of patients after surgical procedures within the upper extremity, e.g.: surgical suturing of damaged finger flexor tendons, treatment of forearm bone fractures, removal of ganglions. The use of therapeutic techniques, including myofascial release, may significantly accelerate the recovery of hand functional in orthopedic afflictions. The pathomechanism of changes in carpal tunnel syndrome also seems to provide a firm basis for the application of the muscle-fascial techniques in the treatment of this condition. In nerve compression syndrome, nerve sliding becomes a constraint, which decreases its resistance to mechanical stress [47]. Adhesions, fibrosis and scars bring about pathomechanical and pathophysiological changes in the nerve [48]. A correlation has also been shown between the pathological mechanic changes within the nerve and its functionality [49].

A therapeutic strategy should also take into account the connections of the transverse carpal ligament with the structures that affect its tension, such as carpal thenar muscles, finger flexor muscle or the long palmar muscle.

The transverse carpal ligament is a collagen line, which restricts the carpal tunnel and also forms the initial attachment for the carpal thenar muscles [50]. It stabilizes the structure of the carpal tunnel [51], acts as a stretcher of flexor muscle tendons [52] and supports the flexibility of the carpal tunnel [53]. It has been shown that the transverse carpal ligament is co-formed by the long palmar muscle, thus its activity will be modelling the tendon's tension. The long palmar muscle is attached to the medial epicondyle of the humerus, while its fascia is connected with the superficial antebrachial fascia [24]. The coracobrachialis, some fibers of which terminate on the medial epicondyle of the humerus, also has attachments to the medial septum of the arm [54], the fibres of which are part of the clavipectoral fasci, surrounding the minor pectoral muscle, and which also integrates into the coracobrachialis fascia [5]. The superficial fascia connections seem to be much simpler. The palmar aponeurosis is connected with the transverse ligament and, farther, it is a continuation of the antebrachial fascia [55]. The antebrachial fascia is a continuation of the brachial fascia, while its tension is modelled by the activity of the brachial biceps muscle, the aponeurosis of which integrates into it. This aponeurosis also covers the medial nerve at the region of the ulnar joint, while its thickening may limit the sliding functionality of the nerve [56].

The brachial fascia receives bundles from the fascia of the greater pectoral muscle [57]. Increased rigidity or thickness of the transverse carpal ligament may result from the activity of repeatable forces, generated by the thenar muscles and the long palmar muscle [58]. It seems that a manual intervention within the structures may decrease their tension and improve their flexibility. In result, decreasing the tension of the transverse carpal ligament and protecting it against changes, leading to its thickening and increased rigidity, may bring about a permanent success of the prophylactic treatment of carpal tunnel syndrome. The application of techniques, intervening into the pathologically changed fascia structures in orthopedic patients, including hand dysfunction, seems to be particularly significant in the therapeutic process. The reduced time of the patient's recovery to full mobility seems to have a number of advantages, both social and economic.

\section{References}

1. Passerieux E, Rossignol R, Chopard A, Carnino A, Marini J F, et al. (2006) Structural organisation of the perimysium in bovine skeletal muscle: junctional plates associated intracellular dubdomains. J Struct Biol 154 (2): 206-216.

2. Stecco C, Porzionato A, Macchi V, Tiengo C, Parenti A, et al. (2006) Histological characteristics of the deep fascia of the upper limb. Italian J Anat Embryol 111(2): 105-110.

3. Guimberteau J C, Armstrong C (2015) Architecture of hu man living fascia: cells and extracellular matrix as revealed by endoscopy. Handspring Pub Ltd ( $1^{\text {st }}$ edn.)., UK.

4. Huijing P D, Langevin H M (2009) Communicating about fascia: history, pitfalls and recommendations. Int J Ther Massage Bodywork 2(4): 3-8.

5. Schleip R, Findley T W, Chaitow L, Huijing P A (2012) Fascia. Examination, prevention and therapy of the fascial network dysfunction. Elsevier Urban \& Partner, Wroclaw Poland.

6. Standring S, Borley N R, Gray H (2008) Gray's anatomy: the anatomical basis of clinical practice. $40^{\text {th }}$ edn. anniversary ed [Edinburgh] Churchill Livingstone Elsevier. 
7. Stecco C, Macchi V, Porzionato A, Duparc F, De Caro R (2011) The fascia: the forgotten structure. Ital J Anat Embryol 116 (3): 127-138.

8. Myers T (2014) Anatomic trials. (3 $3^{\text {rd }}$ Edn.). Churchil Livingstone Elsevier.

9. Findley T, Chaudhry H, Stecco A, Roman M (2012) Fascia research - a narrative review. J Bodyw Mov Ther 16 (1): 67-75.

10. Schleip R (2003) Fascial plasticity - a new neurobiological explanation: Part 1. J Bodyw Mov Ther 7 (1): 11-19.

11. Chaitow L (2009) Research in water and fascia. Micro-tornadoes, hydrogenated diamonds \& nanocrystals. Massage Today 9: 1-3.

12. Stecco C, Gagey O, Belloni A, Pozzuoli A, Porzionato A, et al. (2007) Anatomy of the deep fascia of the upper limb. Second part: study of innervation. Morphologie 91(292): 38-43.

13. Benjamin M (2009) The fascia of the limbs and back - a review. J Anat 214(1): 1-18.

14. Schleip R, Gab biani G, Wilke J, Naylor I, Hinz B, et al. (2019) Fascia is able to actively contract and may thereby influence musculoskeletal dynamics: a histochemical and mechanographic investigation. Front Physiol 10: 336.

15. Hinz B (2010) The myofibroblast: paradigm for a mechanically active cell. J Biomech 43(1): 146-155.

16. Pavan PG, Stecco A, Stern R, Stecco C (2014) Painful connections: densification versus fibrosis of fascia. Curr Pain Headache Rep 18 (8) 441.

17. Stecco C, Pavan P, Pachera P, De Caro R, Natali A (2014) Investigation of the mechanical properties of the human crural fascia and their possible clinical implications. Surg Radiol Anat 36(1): 25-32.

18. Purslow PP (2002) The structure and functional significance of variations in the connective tissue within muscle. Comp Biochem Physiol A Mol Integr Physiol 133(4): 947-966.

19. Meijer HJ, Rijkelijkhuizen JM, Huijing PA (2007) Myofascial force transmission between antagonistic rat lower limb muscles: effects of single muscle or muscle group lengthening. J Electromyogr Kinesiol 17(6): 698-707.

20. Stecco C, Porzionato A, Lancerotto L, Stecco A, Macchi V, et al. (2008) Histological study of the deep fasciae of the limbs. J Bodyw Mov Ther 12 (3): 225-230.

21. Guimberteau JC, Delage JP, Mc Grouther DA, Wong JK (2010) The microvacuolar system: how connective tissue sliding works? J Hand Surg Eur 35(8): 614-622.

22. Hedley G (2008) Demonstration of the integrity of human superficial fascia as an autonomous organ. J Bodyw Mov Ther 12(3): 258.

23. Fourie W (2008) Fascia lata: merely a thigh stocking or a coordinator of complex thigh muscular activity? J Bodyw Mov Ther 12(3): 265.

24. Stecco C, Pavan PG, Porzionato A, Macchi V, Lancerotto L et al. (2009) Mechanics of crural fascia: from anatomy to constitutive modelling. Surg Radiol Anat 31(7): 523-529.

25. Schleip R, Klingler W, Lehmann Horn F (2005) Active fascial contractility: fascia may be able to contract in a smooth muscle - like manner and thereby influence musculoskeletal dynamics. Med Hypotheses 65 (2): 273-277.

26. Kumka M, Bonar J (2012) Fascia: a morphological description and classification system based on a literature review. J Can Chiropr Assoc 56(3): 179-191.

27. Huijing PA, Voermans NC, Baan GC, TE Buse, Baziel G Van E, et al. (2010) Muscle characteristics and altered myofascial force transmission in tenascin-X-deficient mice, a mouse model of Ehlers-Danlos syndrome. J Appl Physiol 109(4): 986-995.
28. Langevin HM, Stevens Tuttle D, Fox JR, Badger GJ, Bouffard NA, et al. (2009) Ultrasound evidence of altered lumbar connective tissue structure in human subjects with chronic low back pain. BMC Musculoskelet Disord 3 (10): 151.

29. Kjaer M, Langberg H, Heinemeier K, Bayer ML, Hansen M, et al. (2009) From mechanical loading to collagen synthesis, structural changes and function in human tendon. Scand J Med Sci Sports 19(4): 500-510.

30. Fede C, Albertin G, Petrelli L, M M Sfrico, C Biz, et al. (2016) Hormone receptor expression in human fascial tissue. Eur J Histochem 60: 2710.

31. Smeulders MJ, Kreulen M (2007) Myofascial force transmission and tendon transfer for patients suffering from spastic paresis: a review and some new observations. J Electromyogr Kinesiol 17(6): 644-656.

32. Bednar DA., Orr FW, Simon GT (1995) Observations on the pathomorphology of the thoracolumbar fascia in chronic mechanical back pain: a microscopic study. Spine 20: 1161-1164.

33. Hedley G (2010) Notes on visceral adhesions as fascial pathology. J Bodyw Mov Ther 14(3): 255-261.

34. Hanten WP, Chandler SD (1994) Effects of myofascial release leg pull and sagittal plane isometric contract-relax techniques on passive straightleg raise angle. J Orthop Sports Phys Ther 20(3): 138-144.

35. Mc Kenney K, Elder AS, Elder C, Hutchins A (2013) Myofascial release as a treatment for orthopedic conditions: a systematic review. J Athl Train 48(4): 522-527.

36. Goyal M, Goyal K, Bathla M, Kanimozhi D, Narkeesh D (2017) Efficacy of myofascial unwinding and myofascial release technique in a patient with somatic symptoms - a case report. Indian J Psychol Med 39 (2): 199-201.

37. Kojidi MM, Okhovatian F, Rahimi A, Baghban AA, Azimi H (2016) Comparison between the effects of passive and active soft tissue therapies on latent trigger points of the upper trapezius muscle in women: single-blind, randomized clinical trial. J Chiropr Med 15(4): 235-242.

38. Park DJ, Hwang YI (2016) A pilot study of balance performance benefit of myofascial release with tennis ball, in chronic stroke patients. J Bodyw Mov Ther 20(1): 98-103.

39. Kalichman L, David CB (2017) Effect of self-myofascial release on myofascial pain, muscle flexibility and strength: a narrative review. J Bodyw Mov Ther 21(2): 446-451.

40. Ajimsha MS, Chithra S, Thulasyammal RP (2012) Effectiveness of myofascial release in the management of lateral epicondylitis in computer professionals. Arch Phys Med Rehabil 93(4): 604-609.

41. Saratchandran R, Desai S (2013) Myofascial release as an adjunct to conventional therapy in mechanical low back pain. Indian J Occup Ther 45: $2-7$

42. Zalta J (2008) Massage therapy protocol for post-anterior cruciate ligament reconstruction patellofemoral pain syndrome: a case report. Int J Ther Massage Bodywork 1(2): 11-21.

43. Muniz E Silva DCC, Andrade Alexandre DJ, Silva JG (2018) Immediate effect of myofascial release on range of motion, pain and biceps and rectus femoris muscle activity after total knee replacement. J Bodyw Mov Ther 22(4): 930-936.

44. Shaw RB Jr, Chong AK, Zhang A, Hentz VR, Chang J (2007) Dupuytren's disease: history, diagnosis, and treatment. Plast Reconstr Surg 120(3): 44-54.

45. Khashan M, Smitham PJ, Khan WS, Goddard NJ (2011) Dupuytren's disease: review of the current literature. Open Orthop J 5(2): 283-288.

46. Jurecka A, Papież M, Pawłowska J, Solecki T, Gądek A (2018) Efficacy evaluation of myofascial release techniques for patients after surgical treatment of Dupuytren's contracture. Medical Review 75(4): 163-168. 
47. Hough AD, Moore A, Jones MP (2007) Reduced longitudinal excursion of the median nerve in carpal tunnel syndrome. Arch Phys Med Rehabil 88(5): 569-576.

48. Mackinnon SE (2002) Pathophysiology of nerve compression. Hand Clin 18(2): 231-241.

49. Shacklock M (2005) Clinical neurodynamics: a new system of musculoskeletal treatment. $1^{\text {st }}$ edn. Oxford: Elsevier pp: 118-121.

50. Shen ZL, Li ZM (2013) Biomechanical interaction between the transverse carpal ligament and the thenar muscles. J Appl Physiol 114(2): 225-229.

51. Xiu KH, Kim JH, Li ZM (2010) Biomechanics of the transverse carpal arch under carpal bone loading. Clin Biomech 25(8): 776-780.

52. Kiritsis PG, Kline SC (1995) Biomechanical changes after carpal tunnel release: a cadaveric model for comparing open, endoscopic, and step-cut lengthening techniques. J Hand Surg Am 20(2): 173-180.

\section{ISSN: 2574-1241}

DOI: $10.26717 /$ BJSTR.2020.29.004874

Alicja Jurecka. Biomed J Sci \& Tech Res

(C) This work is licensed under Creative

Submission Link: https://biomedres.us/submit-manuscript.php
53. Ratnaparkhi R, Xiu KH, Guo X, Li ZM (2016) Changes in carpal tunnel compliance with incremental flexor retinaculum release. J Orthop Surg Res 13(11): 43.

54. Gray H (2018) Gray's Anatomy: the anatomical basis of clinical practice. Editor-in-chief: Susan Standring ( $41^{\text {st }}$ Edn.). Elsevier.

55. Baldoni GC, Bastianini A (2018) Human anatomy. Edi Ermes Milan, Italy.

56. Caetano EB, Vieira LA, Almeida TA, Montero Gonzales LA, de Bona JE, et al. (2018) Bicipital aponeurosis. Anatomical study and clinical implications. Rev Bras Ortop 53(1): 75-81.

57. Baig MA, Bordoni B (2020) Anatomy shoulder and upper limb, pectoral muscles. Treasure Island, NCBI, StatPearls Publishing, Florida.

58. Wang JH (2006) Mechanobiology of tendon. J Biomech 39(9): 15631582.

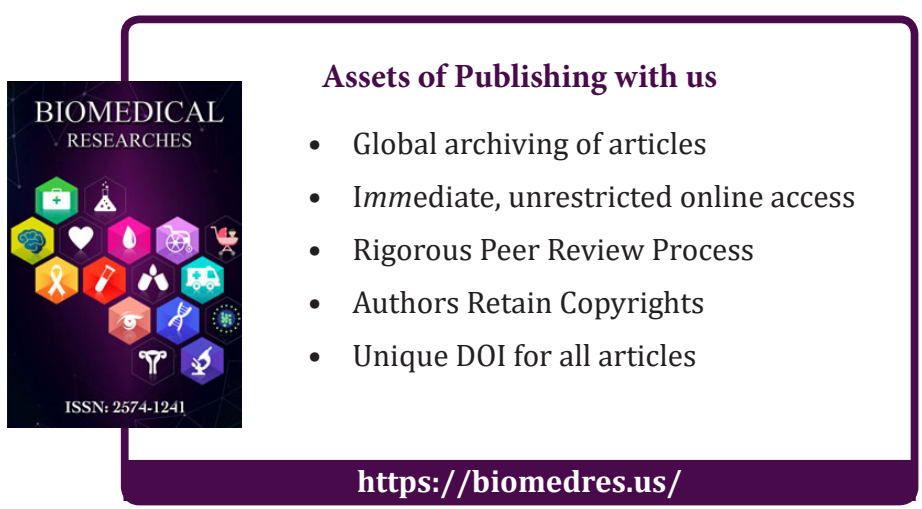

